\title{
THE ESTIMATION OF COCOANUT OIL IN BUTTER.
}

\author{
By RAYMOND ROSS, F.I.C. \\ (Read at the Meeting, November 4, 1908.)
}

[The title of this paper is perhaps somewhat misleading, for, although the investigation was originally undertaken with a view to the estimation of cocoanut oil, the net result is only to throw some light on the composition of certain butters and cocoanut oils. I trust, however, these results may not be without interest.]

E. Hinks (Analyst, 1907, 32, 60) has described a method for the determination of cocoanut oil in butter based on the microscopical examination of the soluble residue obtained by freezing out the fat from ether and alcohol. It appeared to me that this process might be made quantitative, and the proportion of cocoanut oil estimated by a determination of the constants of the residue. It is generally admitted that cocoanut oil is much more soluble than butter-fat, and a sample that I obtained did not freeze out at all under the conditions to be indicated later, nor did the fatty acids of this oil when similarly treated. This led me to think that practically the whole of the cocoanut oil might be concentrated into a filtrate, and that many of the substances contained in butter would be removed.

Experiments with pure fatty acids further showed that oleic, myristic, and lauric acids were all easily soluble even at fairly low temperatures, while stearic and palmitic acids are less so, their solubility decreasing rapidly with the lowering of temperature. The above remarks also apply to alcoholic solutions of these acids.

As the question of volatile fatty acids has been practically dealt with in the investigations of the Polenske method, I decided to confine my efforts to the insoluble fatty acids, which, of course, constitute by far the larger proportion of the fats under consideration. After various experiments the method adopted was as follows :

Four grams of the fatty acids were dissolved in 20 c.c. of ether, and cooled in a freezing mixture of salt and ice to $-15^{\circ} \mathrm{C}$. The frozen-out portion was then stirred, with the addition of 10 c.c. of ether, at a temperature of $-15^{\circ} \mathrm{C}$. and rapidly filtered. The ether was evaporated from the filtrate, and the residue so obtained treated with alcohol in an exactly similar manner. The alcohol was removed by evaporation on the water-bath, and the Zeiss butyro-refractometer reading of the residue recorded.

Experiments on these lines on butters adulterated with cocoanut oil (later referred to as original sample) gave satisfactory results. A butter of known origin and six samples received under the Food and Drugs Acts were used for the purpose of obtaining constants. Later, Mr. Bevan kindly sent me four test samples H, G, C, O) containing unknown quantities of cocoanut oil. 
The following results were obtained :

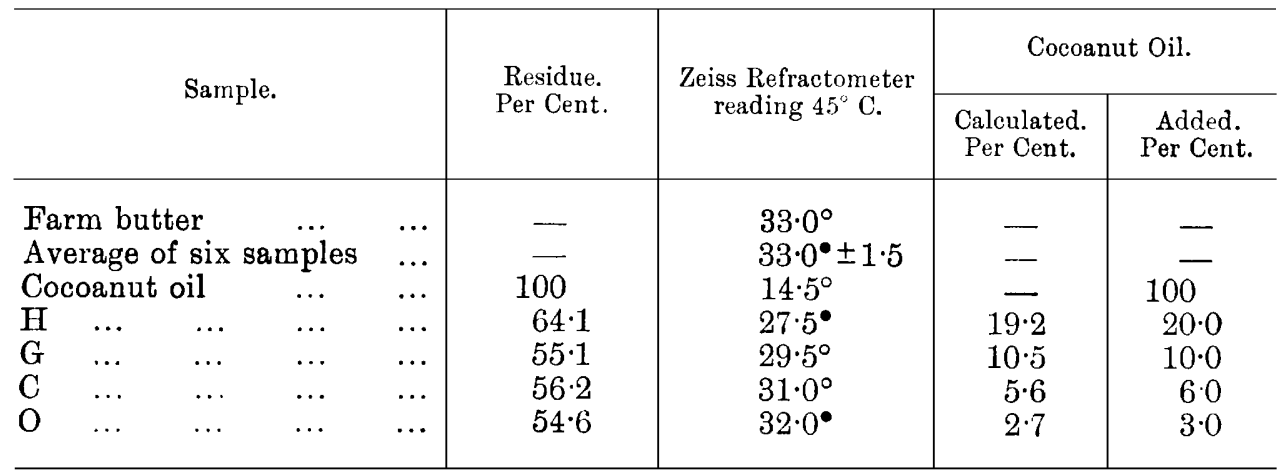

The method of calculation was based on the assumption that the whole of the cocoanut oil was present in the filtrate, and that 33.0 and 14.5 respectively were the refractometer readings for the residues from pure butter and cocoanut oil fatty acids. The process having proved so far satisfactory, it was desirable to test it further with foreign butters of known origin. The following samples were examined in a similar manner :

\begin{tabular}{|c|c|c|c|c|c|c|c|}
\hline \multicolumn{4}{|c|}{ Sample. } & $\begin{array}{c}\text { Residue. } \\
\text { Per Cent. } \\
61\end{array}$ & $\begin{array}{c}\text { Zeiss } \\
\text { Refractometer } \\
\text { Reading } \\
\mathbf{4 5}^{\circ} \mathrm{C} .\end{array}$ & $\begin{array}{c}\begin{array}{c}\text { Iodine } \\
\text { Absorption. }\end{array} \\
30 \cdot 0\end{array}$ & $\begin{array}{c}\begin{array}{c}\text { Oleic Acid } \\
\text { calculated } \\
\text { per Cent. }\end{array} \\
33 \cdot 3\end{array}$ \\
\hline $\begin{array}{ll}\text { Finnish } & \ldots \\
\text { Argentine } & . . \\
\text { Danish } & \ldots \\
\text { Siberian } & \ldots \\
\text { Swedish } & \ldots \\
\text { Irish salt } & . .\end{array}$ & $\begin{array}{l}\cdots \\
\cdots \\
\cdots \\
\cdots \\
\cdots \\
\cdots\end{array}$ & $\begin{array}{l}\cdots \\
\cdots \\
\cdots \\
\cdots \\
\cdots \\
\cdots\end{array}$ & $\begin{array}{l}\cdots \\
\cdots \\
\cdots \\
\cdots \\
\cdots \\
\cdots\end{array}$ & $\begin{array}{l}61 \\
69 \\
57 \\
62 \\
52 \\
40\end{array}$ & $\begin{array}{l}26^{\circ} \\
28^{\circ} \\
31^{\circ} \\
27^{\circ} \\
33^{\circ} \\
34^{\circ}\end{array}$ & $\begin{array}{l}30 \cdot 0 \\
32 \cdot 4 \\
39 \cdot 0 \\
30 \cdot 0 \\
45 \cdot 6 \\
47 \cdot 8\end{array}$ & $\begin{array}{l}33 \cdot 3 \\
36 \cdot 0 \\
43 \cdot 3 \\
33 \cdot 3 \\
50 \cdot 6 \\
53 \cdot 1\end{array}$ \\
\hline
\end{tabular}

From these results it is evident that the process completely breaks down, but it was thought that some relationship might exist if the refractions due to unsaturated fatty acids (calculated as oleic acid from the iodine value) were allowed for. For this purpose the iodine values of the residues given in the first table were determined:

\begin{tabular}{|c|c|c|c|c|c|c|c|}
\hline \multicolumn{2}{|c|}{ Sample. } & & & & \multicolumn{2}{|l|}{$\begin{array}{l}\text { Iodine } \\
\text { Value. }\end{array}$} & \multirow{2}{*}{$\begin{array}{c}\text { Oleic Acid. } \\
\text { Per Cent. } \\
53 \cdot 3\end{array}$} \\
\hline Englis & $\mathrm{rm}$ & & $\cdots$ & & $48 \cdot 0$ & $\ldots$ & \\
\hline Cocoar & oil & $\ldots$ & $\cdots$ & $\ldots$ & $8 \cdot 0$ & $\ldots$ & $8 \cdot 9$ \\
\hline H $\quad \ldots$ & $\ldots$ & $\ldots$ & $\ldots$ & $\ldots$ & $36 \cdot 4$ & $\ldots$ & $40 \cdot 4$ \\
\hline$\ldots$ & $\ldots$ & $\ldots$ & $\ldots$ & $\ldots$ & $39 \cdot 6$ & $\ldots$ & $44 \cdot 0$ \\
\hline ... & $\ldots$ & $\ldots$ & $\ldots$ & $\ldots$ & $44 \cdot 4$ & $\ldots$ & $49 \cdot 3$ \\
\hline$\ldots$ & $\ldots$ & $\ldots$ & $\ldots$ & $\ldots$ & $47 \cdot 1$ & $\ldots$ & $52 \cdot 3$ \\
\hline
\end{tabular}

The refractometer reading for oleic acid at $45^{\circ} \mathrm{C}$. was found to be 41.5 , or Nd 1.4534. Some of the readings were calculated into the refractive indices, and 
the amount due to unsaturated acids deducted, and the refraction of the saturated acids thus obtained:

\begin{tabular}{llllll}
$\begin{array}{c}\text { Sample } \\
\text { Fatty Acids. }\end{array}$ & & & \multicolumn{3}{c}{$\begin{array}{c}\text { Refractive Index } \\
\text { less Oleic Acid. }\end{array}$} \\
English farm $\ldots$ & $\ldots$ & $\ldots$ & $\ldots$ & $\ldots$ & $1 \cdot 4405$ \\
English Yeovil... & $\ldots$ & $\ldots$ & $\ldots$ & $\ldots$ & $1 \cdot 4391$ \\
Cocoanut oil $\ldots$ & $\ldots$ & $\ldots$ & $\ldots$ & $\ldots$ & $1 \cdot 4321$ \\
Sample H $(20$ per cent.) & $\ldots$ & $\ldots$ & $\ldots$ & $1 \cdot 4365$
\end{tabular}

From the above it is clear that the refractions of the residues obtained after freezing out differ very little except as regards the amount of unsaturated fatty acids present.

It now became advisable to attempt to determine approxinately the composition of various butters and cocoanut oils. For this purpose pure southern butter (Yeovil), Finnish, Siberian, and two cocoanut oils obtained from different sources, were selected. The fatty acids of these samples were each frozen out as before, using a concentration of 10 grams in 50 c.c., both of ether and alcohol, and 20 c.c. of ether for washing purposes. The residues were all collected, dried, and weighed, and their constants determined. The results of these determinations are given in the following tables. In every case the molecular weight of the saturated fatty acids, corrected for unsaturated fatty acids calculated as oleic acid, is given under the heading $\mathrm{M}-\mathrm{O}$. For sake of comparison a number of constants of certain pure fatty acids are also given :

Original Samples.

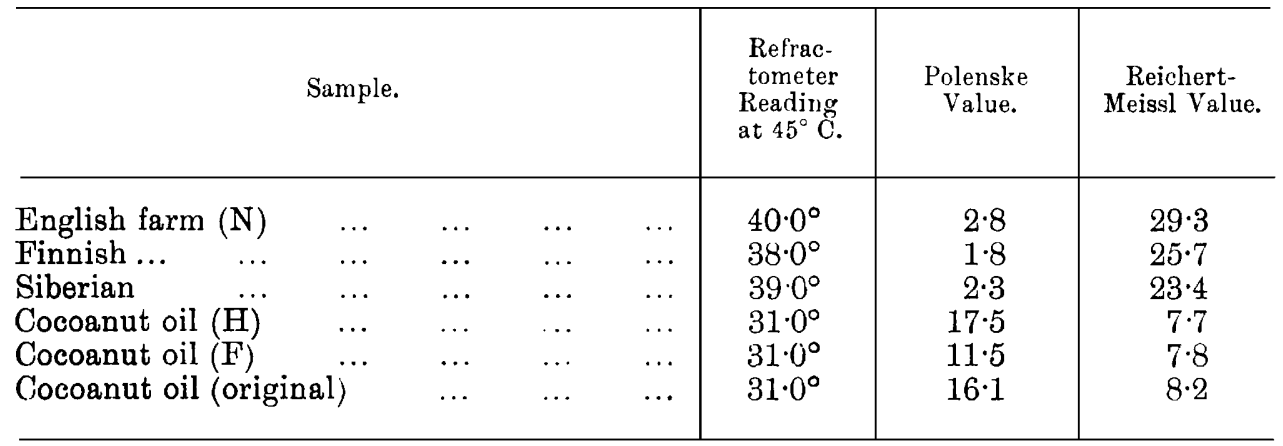

Insoluble Volatile Fatty Acids.

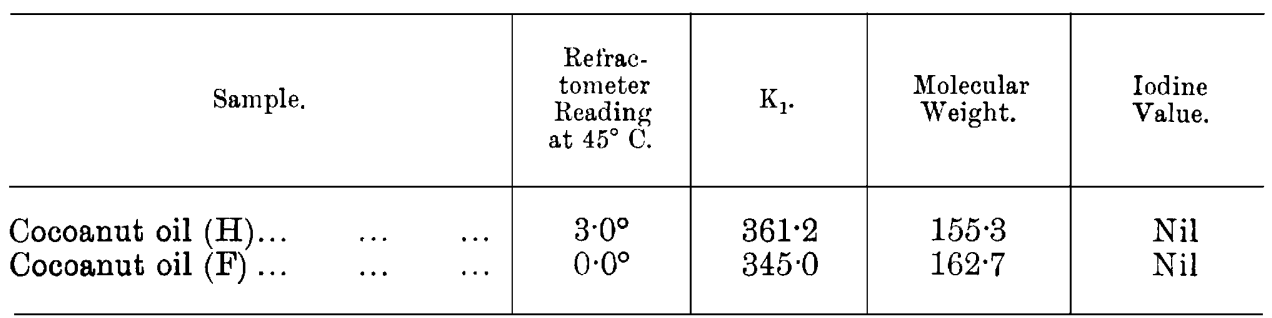


Original Fatty Acids.

\begin{tabular}{|c|c|c|c|c|c|c|c|}
\hline Sample. & $\begin{array}{l}\text { Refrac- } \\
\text { tometer } \\
\text { Reading } \\
\text { at } 45^{\circ} \mathrm{C} .\end{array}$ & $\begin{array}{l}\text { Refrac- } \\
\text { tometer } \\
\text { Reading } \\
\text { at } 60^{\circ} \mathrm{C.}\end{array}$ & $\begin{array}{l}\text { Iodine } \\
\text { Value. }\end{array}$ & $\mathrm{K}_{1}$. & $\begin{array}{l}\text { Molecular } \\
\text { Weight. }\end{array}$ & $\mathrm{M}-\mathrm{O}$ & $\begin{array}{l}\text { Percentage } \\
\text { frozen out. }\end{array}$ \\
\hline Yeovil butter $(\mathrm{S}) \quad \ldots$ & $30 \cdot 0^{\circ}$ & - & $45 \cdot 9$ & $207 \cdot 2$ & $270 \cdot 7$ & $258 \cdot 9$ & - \\
\hline Finnish $,, \ldots, \quad \ldots$ & $24 \cdot 0^{\circ}$ & 一 & $39 \cdot 7$ & $207 \cdot 2$ & $270 \cdot 7$ & $261 \cdot 6$ & - \\
\hline Siberian,,$\ldots$ & $29 \cdot 0^{\circ}$ & - & $42 \cdot 2$ & $198 \cdot 8$ & $280 \cdot 2$ & $278 \cdot 6$ & - \\
\hline Cocoanut oil $(\mathrm{H})$ & $17 \cdot 0^{\circ}$ & - & $8 \cdot 9$ & $254 \cdot 8$ & $220 \cdot 1$ & $213 \cdot 2$ & - \\
\hline Cocoanut oil $(\mathrm{F})$ & $24 \cdot 0^{\circ}$ & 一 & $8 \cdot 8$ & $244 \cdot 3$ & $229 \cdot 6$ & $223 \cdot \overline{8}$ & - \\
\hline Cocoanut oil (original) & $16 \cdot 0^{\circ}$ & - & $8 \cdot 8$ & - & - & - & - \\
\hline
\end{tabular}

Residues From Ether.

\begin{tabular}{|c|c|c|c|c|c|c|c|}
\hline Yeovil butter & - & $20 \cdot 0^{\circ}$ & $14 \cdot 3$ & $212 \cdot 7$ & $264 \cdot 1$ & $260 \cdot 7$ & $22 \cdot 0$ \\
\hline Finnish , . & - & $20 \cdot 5^{\circ}$ & $24 \cdot 2$ & $187 \cdot 8$ & $298 \cdot 7$ & $305 \cdot 0$ & $12 \cdot 5$ \\
\hline Siberian & & $25 \cdot 0^{\circ}$ & $41 \cdot 1$ & $188 \cdot 8$ & $296 \cdot 8$ & $309 \cdot 3$ & 36 \\
\hline Cocoanut oil (H) & $20 \cdot 0^{\circ}$ & $12 \cdot 0^{\circ}$ & $6 \cdot 7$ & $224 \cdot 2$ & $229 \cdot 7$ & 225 & 64 \\
\hline Cocoanut oil (F) & - & - & $3 \cdot 1$ & $198 \cdot 5$ & $282 \cdot 6$ & $32 \cdot 6$ & \\
\hline $\begin{array}{l}\text { Yeovil butter }+20 \text { per } \\
\text { cent. cocoanut oil }\end{array}$ & $28 \cdot 0^{\circ} \mathrm{C}^{*}$ & $19 \cdot 0^{\circ} c^{*}$ & $8 \cdot 0$ & 2240 & $250 \cdot 4$ & $247 \cdot 3$ & \\
\hline
\end{tabular}

Residues from Alcohol.

\begin{tabular}{ll|l|c|c|c|c|c|c} 
Yeovil butter & $\ldots$ & $29 \cdot 0^{\circ} 0^{*}$ & $21 \cdot 0^{\circ}$ & $13 \cdot 6$ & $205 \cdot 1$ & $273 \cdot 5$ & $272 \cdot 0$ & $12 \cdot 0$ \\
Finnish,$\quad \ldots$ & $\ldots$ & $23 \cdot 5^{\circ}$ & $15 \cdot 5^{\circ}$ & $31 \cdot 7$ & $205 \cdot 8$ & $272 \cdot 6$ & $267 \cdot 5$ & $22 \cdot 1$ \\
Siberian,$\ldots$ & $\ldots$ & $27 \cdot 0^{\circ}$ & $19 \cdot 0^{\circ}$ & $39 \cdot 7$ & $212 \cdot 2$ & $263 \cdot 6$ & $249 \cdot 1$ & $27 \cdot 5$ \\
Cocoanut oil (H) & $\ldots$ & - & - & - & - & - & - & $\mathrm{Nil}$ \\
Cocoanut oil (F) & $\ldots$ & $25 \cdot 0^{\circ}$ & - & $6 \cdot 6$ & $235 \cdot 2$ & $238 \cdot 5$ & $235 \cdot 1$ & $59 \cdot 6$ \\
$\begin{array}{l}\text { Yeovil butter +20 per } \\
\text { cent. cocoanut oil }\end{array}$ & $28 \cdot 5^{\circ}$ & - & $25 \cdot 9$ & $226 \cdot 8$ & $247 \cdot 4$ & $233 \cdot 4$ & $45 \cdot 7$
\end{tabular}

Unfreazable Residues.

Percentage left.

\begin{tabular}{|c|c|c|c|c|c|c|c|}
\hline Yeovil butter & $34.0^{\circ}$ & $26^{\circ} 0^{\circ}$ & $56 \cdot 6$ & $216 \cdot 4$ & $259 \cdot 2$ & 220.5 & $66 \cdot 0$ \\
\hline Finnish ," & $25 \cdot 0^{\circ}$ & $17 \cdot 0^{\circ}$ & $38 \cdot 6$ & $205 \cdot 8$ & $272 \cdot 6$ & $265 \cdot 5$ & $65 \cdot 4$ \\
\hline Siberian , & $29 \cdot 5^{\circ}$ & $21 \cdot 5^{\circ}$ & $47 \cdot 1$ & $209 \cdot 3$ & $268 \cdot 0$ & $252 \cdot 7$ & $36 \cdot 4$ \\
\hline Cocoanut oil $(\mathrm{H})$ & $15 \cdot 5^{\circ}$ & $8 \cdot 0^{\circ}$ & $8 \cdot 4$ & $266^{\circ} 0$ & $210 \cdot 9$ & $203 \cdot 6$ & $35 \cdot 9$ \\
\hline Cocoanut oil $(\mathrm{F})$ & $22 \cdot 0^{\circ}$ & - & $6 \cdot 0$ & $253 \cdot 3$ & $221 \cdot 5$ & $217 \cdot 1$ & $26 \cdot 1$ \\
\hline $\begin{array}{l}\text { Yeovil butter }+20 \text { per } \\
\text { cent. cocoanut oil }\end{array}$ & $32 \cdot 5^{\circ}$ & - & $44: 9$ & $226 \cdot 5$ & $247 \cdot 7$ & 213.5 & $40 \cdot 7$ \\
\hline
\end{tabular}

* Calculated from the higher temperature reading. 
THE ANALYST。

Constants of Fatty Acids.

\begin{tabular}{lll|c|c|c}
\hline \multicolumn{2}{c|}{ Acid. } & & $\begin{array}{c}\text { Refractometer Reading } \\
\text { at } 45^{\circ} \mathrm{C}\end{array}$ & $\begin{array}{c}\text { Refractometer Reading } \\
\text { at } 75^{\circ} \mathrm{C} .\end{array}$ & $\begin{array}{c}\text { Molecular } \\
\text { Weight. }\end{array}$ \\
\hline Stearic & $\ldots$ & $\ldots$ & $30 \cdot 0^{\circ} c^{*}$ & $12 \cdot 0^{\circ}$ & 284 \\
Palmitic & $\ldots$ & $\ldots$ & $26 \cdot 5^{\circ} c^{*}$ & $8 \cdot 5^{\circ}$ & 256 \\
Oleic ... & $\ldots$ & $\ldots$ & $41 \cdot 5^{\circ}$ & $25 \cdot 5^{\circ}$ & 282 \\
Myristic & $\ldots$ & $\ldots$ & $25 \cdot 5^{\circ} c^{*}$ & $7 \cdot 5^{\circ}$ & 228 \\
Lauric ... & $\ldots$ & $\ldots$ & - & - & 200 \\
Capric ... & $\ldots$ & $\ldots$ & - & - & 172 \\
Caprylic & $\ldots$ & $\ldots$ & - & - & 144 \\
Caproic & $\ldots$ & $\ldots$ & - & & 116 \\
\hline
\end{tabular}

From the above figures it is evident that, with the exception of oleic acid, the Zeiss refractometer figures are not sufficiently distinctive to be of much service. On the assumption that, besides oleic acid, only two acids are present in each fraction, the approximate composition has been calculated from a consideration of the iodine value, as a measure of the oleic acid, and from the percentages frozen out. The nature of the two remaining acids was derived from the molecular weights of the saturated fatty acids in the column $\mathrm{M}-\mathrm{O}$. These figures are given below :

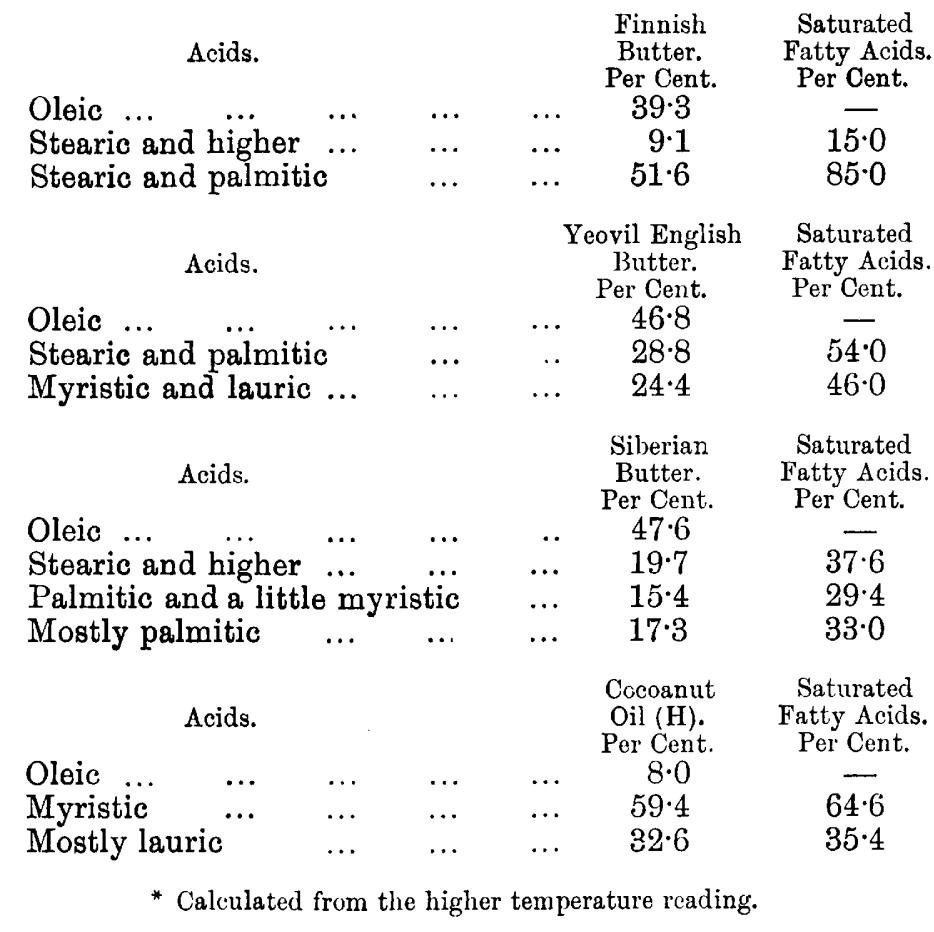




\begin{tabular}{lllllcc}
\multicolumn{2}{c}{ Acids. } & & & & $\begin{array}{c}\text { Cocoanut } \\
\text { Oil (F). } \\
\text { Per Cent. }\end{array}$ & $\begin{array}{c}\text { Saturated } \\
\text { Fatty Acids. } \\
\text { Per Cent. }\end{array}$ \\
Oleic ... & $\ldots$ & $\ldots$ & $\ldots$ & $\ldots$ & $6 \cdot 6$ & - \\
Stearic & $\ldots$ & $\ldots$ & $\ldots$ & $\ldots$ & $13 \cdot 8$ & $14 \cdot 8$ \\
Palmitic and myristic & $\ldots$ & $\ldots$ & $55 \cdot 3$ & $59 \cdot 3$ \\
Myristic and lauric & $\ldots$ & $\ldots$ & $24 \cdot 3$ & $25 \cdot 9$
\end{tabular}

From a consideration of the above tables, it seems probable that, as regards the insoluble fatty acids, the variations in the composition of different butters and cocoanut oils are so great among themselves that the fixing of reliable constants becomes practically an impossibility. In some instances there is little difference between butters and cocoanut oils, except as regards the amount of unsaturated acids present. Thus, cocoanut oil (F) approaches so nearly to English butter ( $Y$ ) that an addition of 20 per cent. of it to the butter gave but a very slight indication in any of the constants.

As regards the unsaturated fatty acids, these seem to be the principal cause of the variations in the refractions on the unfreezable residues, and this determination is therefore useless.

It is evident that the same saturated fatty acids are present in nearly all cases, although in variable quantities. The butters from the northern countries contain less oleic acid, and probably in some instances a higher acid than stearic.

A further attempt was made to examine the saturated fatty acids as a whole by removing the oleic acid.

Ten grams of the fatty acids were treated with excess of a concentrated Hübl solution, and the iodo-compound separated in hot brine by difference in density from the saturated fatty acids. The latter were then saponified, reprecipitated, and filtered. The following constants were obtained, but the differences are too small to allow of any accurate deductions:

\begin{tabular}{|c|c|c|c|c|}
\hline Sample. & & $\begin{array}{l}\text { Saturated } \\
\text { Fatty Acids. }\end{array}$ & & $\begin{array}{l}\text { Molecular } \\
\text { Weight. }\end{array}$ \\
\hline Fin & & $\ldots \quad 58 \cdot 6$ & & $256 \cdot 0$ \\
\hline oil $(\mathrm{F})$ & $\cdots$ & $\ldots 90 \cdot 0$ & $\cdots$ & $215 \cdot 0$ \\
\hline Cocoanut oil $\left(\mathrm{H}^{\prime}\right)$ & & $\ldots 87 \cdot 0$ & . & $210 \cdot 7$ \\
\hline
\end{tabular}

These figures tend to confirm the previous ones, and seem to show the futility of attempting to differentiate between cocoanut oil and butter by any consideration of the characteristics of their insoluble fatty acids.

In conclusion, I wish to thank my assistant, Mr. F. Maudsley, for the assistance he has rendered in carrying out this investigation.

\section{Discussion.}

Mr. F. W. Richardson asked whether the author had met with many samples of butter with abnormally high Polenske numbers. For a long time the Polenske numbers which he (the speaker) had been obtaining had been normal, but some years ago a number of samples from one district had given Polenske numbers as high as $4 \frac{1}{2}$, 
and as all the other data pointed to the presence of cocoanut oil he had felt bound to condemn those samples. No sample with an abnormally high Polenske number had since come to him from that district, and he had never since met with a butter showing indications of cocoanut oil. It would be interesting if the author could account for the method giving such good results with the samples provided by Mr. Bevan while it broke down with other samples.

Mr. Hehner said that at one time, in conjunction with Mr. C. A. Mitchell, he had made some hundreds of determinations of stearic acid in butter, and their conclusion was that butter, as a general rule, contained less than 1 per cent. of stearic acid, although certain exceptions, due to abnormality, made this fact useless for the object they had in view. These exceptions occurred in the case of some Russian samples with very low Reichert-Wollny figures.

Mr. E. R. BoLton asked whether the author had made any experiments with butter containing other fats in addition to cocoanut oil. Probably cocoanut oil was not very often added alone to butter; at any rate he had never met with such a case. It would almost certainly be added in conjunction with other fats in the form of margarine, which might considerably alter the conditions as to solubility.

Mr. Ross said that as regards Mr. Bevan's samples the probability seemed to be that in those cases the butter was either from the North of England or from Ireland. All the Irish butters he had examined had behaved normally. With Danish butter, too, good results would probably be obtained. The highest Polenske number he had ever found was about $3 \cdot 0$. In the cases now referred to the highest was $2 \cdot 8$, and it would probably be considerably lower than that in butter from northern countries. He had been making experiments with about half a dozen fats other than cocoanut oil, but had not yet had time to complete them.

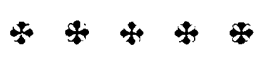

